Farm animal welfare - who writes the rules?

Occasional Publication No. 23 - British Society of Animal Science 1999

edited by A. J. F. Russel, C. A. Morgan, C. J. Savory, M. C. Appleby and T. L. J. Lawrence

\title{
Chronic inflammatory responses of lambs to rubber ring castration: are there any effects of age or size of lamb at treatment?
}

\author{
J. E. Kent ${ }^{1}$, V. Molony ${ }^{1}$, R. E. Jackson ${ }^{1}$ and B. D. Hosie ${ }^{2}$ \\ ${ }^{1}$ Department of Preclinical Veterinary Sciences, University of Edinburgh, Royal (Dick) School of Veterinary Studies, \\ Summerhall, Edinburgh EH9 1QH \\ ${ }^{2}$ Scottish Agricultural College, Veterinary Investigation Services, Bush Estate, Penicuik, Midlothian EH26 OQE
}

\section{Introduction}

In the United Kingdom (UK), rubber rings can only be used to castrate and/or tail dock lambs under 1 week of age. Some hill sheep farmers find it impractical to carry out these procedures at this age. Small differences occur in the behavioural and plasma cortisol response to the acute pain caused by the rubber ring in lambs under a week of age compared with those at 6 weeks old (Kent et al., 1993; Molony et al., 1993) and the Farm Animal Welfare Council (FAWC, 1994) recommended that use of the rubber ring method should be permitted on lambs up to 6 weeks of age. However, we have shown previously that the rubber ring acts as a foreign body at the neck of the scrotum and can, for 4 to 6 weeks after application, produce septic lesions in calves (Molony et al., 1995) and 6-week-old lambs (Kent et al., 1997). These lesions are accompanied by behavioural changes considered to be indicative of chronic pain. This paper brings together three studies in order to compare the chronic inflammatory effects of rubber ring castration in 2-day (the current practice of many lowland sheep farmers), 28-day (an age which might be practical for hill sheep farmers) and 42-day-old housed lambs.

\section{Material and methods}

Suffolk or Dorset cross Dorset/Finn lambs, less than 2 days of age, were castrated and tail docked using the standard elastrator rings (Paragon), half using local anaesthetic applied by needleless injection $(1.2 \mathrm{ml}$ total) $(\mathrm{RR})$ (no. $=10$ ). A further 10 lambs acted as non-castrated/tail docked control lambs $(\mathrm{H})$ for behavioural observations only. Two groups of eight 28-day-old lambs of the same breed were castrated using standard rubber rings. Each group was subjected to a different method for the reduction of acute pain as part of another study. The groups were castration using local anaesthetic, applied by multishot injector ( $2 \mathrm{ml}$ ) (RRms) or Panjet needleless injector $(1.2 \mathrm{ml})$ (Rrpan). The results of this study will be published elsewhere. Only the chronic effects are considered here. Only eight lambs castrated by rubber ring (RR) with local anaesthetic $(50 \%$ from each method) were observed for behaviour, together with their uncastrated twin $(\mathrm{H})$. Results from 2-day and 28-day-old lambs are compared with the values obtained previously from 42-day-old Scottish Blackface (SBF) lambs (Kent et al., 1997).

The rubber ring acted as a foreign body at the neck of the scrotum, causing a lesion that, twice weekly after treatment, was measured (lateral width $(\mathrm{mm})$ ) and scored for the presence of swelling (0 to 2.0), inflammation (2.5 to 3.0$)$ and infection (3.5 to 5.0$)$.

Behavioural observations were carried out by four persons for two 3-h periods (between $14.00 \mathrm{~h}$ and $21.00 \mathrm{~h}$ ) weekly for the 28-day-old lambs and after $10,20,31$ and 42 days for the 2-day-old lambs. A 'playbox' for the lambs to jump on was placed in the pens for the second 3-h period. The frequency of occurrence of tail wagging, easing quarters, foot stamping, kicking, itching quarters, head turning, particularly to the scrotum and inside hindleg, lying down, standing up and playing on the box were recorded continuously and the lambs' posture was

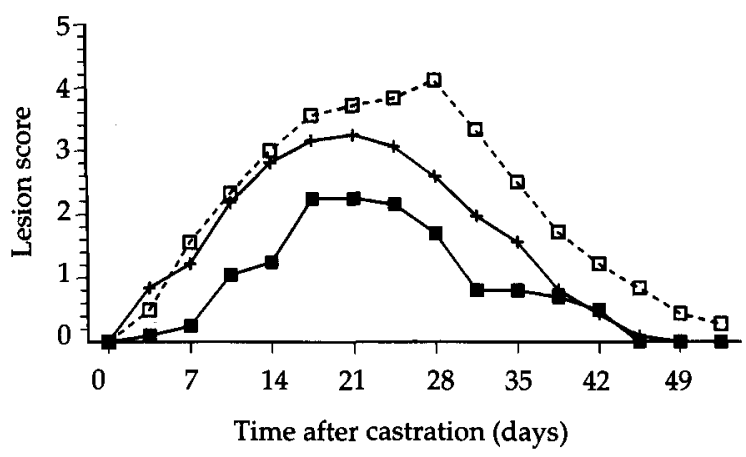

Figure 1 The change in average lesion score with time after rubber ring castration of lambs at 2 days $(\square), 28$ days (+) and 42 days $(\square)$ of age. 
Table 1 The effect of age at castration using elastrator rings on the mean time of the scrotum to drop off and the mean maximum lesion size and clinical score

\begin{tabular}{|c|c|c|c|c|c|c|}
\hline $\begin{array}{l}\text { Age at } \\
\text { castration } \\
\text { (days) }\end{array}$ & Breedt & no. & $\begin{array}{l}\text { Time for } \\
\text { scrotum to } \\
\text { drop off } \\
\text { (days) }\end{array}$ & $\begin{array}{l}\text { Percentage of lambs } \\
\text { with scrotum 'off' } \\
28 \text { days after } \\
\text { treatment }\end{array}$ & $\begin{array}{l}\text { Lesion } \\
\text { score }\end{array}$ & $\begin{array}{l}\text { Lateral } \\
\text { with } \\
\text { (mm) }\end{array}$ \\
\hline $\begin{array}{r}2 \\
28 \\
42\end{array}$ & $\begin{array}{c}\text { Dorx } \\
\text { Dorx } \\
\text { SBF } \\
\text { F-valuef }\end{array}$ & $\begin{array}{l}10 \\
16 \\
16\end{array}$ & $\begin{array}{c}31 \\
34 \\
35 \\
1.6(P>0.05)\end{array}$ & $\begin{array}{c}60 \\
69 \\
94 \\
2 \cdot 4(P>0 \cdot 05)\end{array}$ & $\begin{array}{c}3 \cdot 1^{\mathrm{a}} \\
3 \cdot 6^{\mathrm{a}} \\
4 \cdot 2^{\mathrm{b}} \\
11 \cdot 8(P<0 \cdot 001)\end{array}$ & $\begin{array}{c}18^{\mathrm{a}} \\
21^{\mathrm{a}} \\
27^{\mathrm{b}} \\
18 \cdot 6(P<0.001)\end{array}$ \\
\hline
\end{tabular}

+ Dorx: Dorset or Suffolk $\times$ Dorest-Finn lambs; SBF: pure Scottish Blackface or Greyface lambs.

$\ddagger$ F-value from the analysis of variance and the probability of a significant difference between groups: different superscripts within columns represent values significantly different from each other $(P<0.05)$.

recorded every 6 min (Noldus Observer program). A one-way analysis of variance was used to analyse the lesion parameters.

\section{Results and discussion}

The average clinical score of the lesion increased less in 2-day-old lambs than either in 28-day-old lambs or in 42-day-old Scottish Blackface lambs (Figure 1). In 2-day and 28-day-old lambs there was no significant difference between the mean time taken for the scrotum to drop-off, the mean maximum lesion score or the mean maximum width of the lesion (Table 1). In 42-day-old lambs the lesion was larger as was the mean maximum width of the lesion (Table 1). In 42day-old lambs the lesion was larger (Figure 2 and Table 1) and more likely to become infected although the scrotum did not take much longer to drop off. For Dorset lambs only, there was a correlation $(r=+0.51)$ between the maximum lesion width recorded $(y)$ and the weight $(\mathrm{kg})$ of lamb $(x)$ at castration $y=15 \cdot 8+0 \cdot 44 x$.

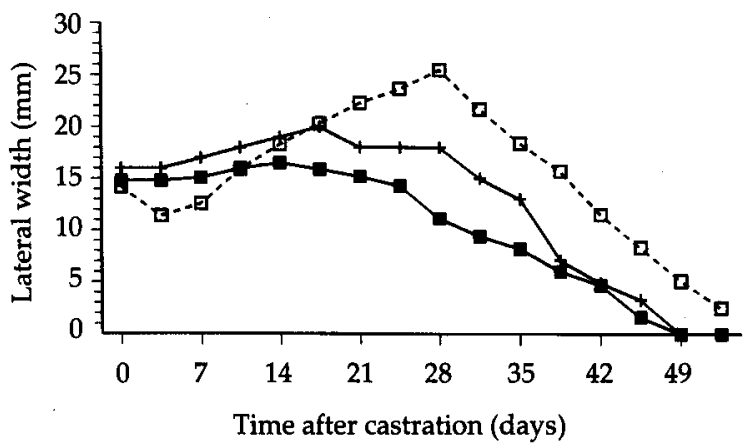

Figure 2 The change in average width of scrotal lesion after rubber ring castration of lambs at 2 days $(\square), 28$ days $(+)$ and 42 days (D) of age.

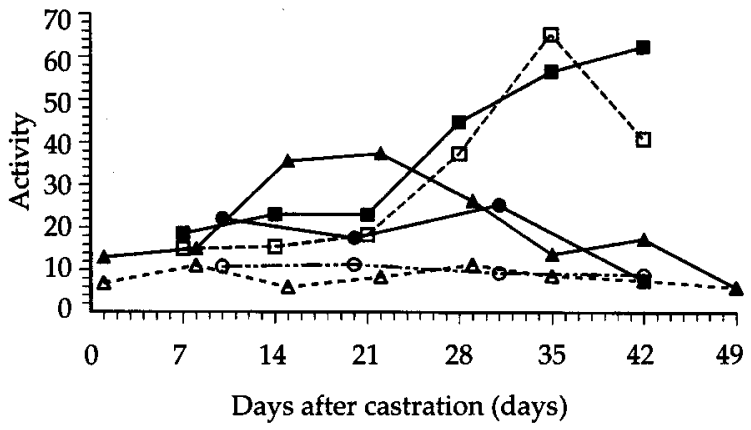

Figure 3 The change in the average behavioural activity (food stamping, kicking, itching quarters, easing quarters and tail wagging summed) recorded in a 6 - $h$ period after rubber-ring castration of lambs at 2 days $(0,0), 28$ days $(\square, \square)$ and 42 days $(\Delta, \Delta)$ of age: $H$ - handled control lambs (open symbols); RR - rubber-ring castrated lambs (closed symbols).

The only behaviours which significantly $(P<0.05)$ increased in 2-day-old castrated lambs were head turning to the scrotum and inside hindleg (medians for an average 6-h period $0 \cdot 3 v \cdot 1 \cdot 8, \mathrm{H} v . \mathrm{RR}$ ) and the combined frequency of foot stamping, kicking, easing quarters, itching quarters and tail wagging (medians 9 v. 16.3), though none of these activities was significantly increased on their own. The only active behaviour significantly increased $(P<0 \cdot 05)$, in 28-day-old treated lambs (RR) was the incidence of head turning, particularly to the scrotal region (medians $0 v .0 .3$ for $\mathrm{H} v$. RR treated lambs). In both 2-day and 28-day-old lambs there was no clear relationship between the active behaviours and the change with time in the clinical score and size of lesion as seen for 6-week-old castrated lambs (Figure 3 ). The increase in active behaviours in the 28-dayold lambs also occurred in the control lambs and was related to a change in the source of the straw bedding. 
In lambs of all ages studied, the rubber ring at the neck of the scrotum acted as a 'foreign body', resulting in an inflammatory lesion which was larger and more likely to become septic in the older lambs. There was no significant difference between 2-day and 28-day-old lambs in the time taken for the scrotum to drop off, the size or clinical score of the lesion. There was a weaker relationship between the behaviours and the changing lesion score in 2-day and 28-day-old Dorset cross lambs compared with that found for 42-day-old SBF lambs suggesting that the smaller lesion may be a less aversive stimulus than the larger, infected lesion found in the older SBF lambs or that the measuring system was insufficiently sensitive. Further investigation of the sensitivity of the measuring system and of the effects of age, breed and size of lamb at castration will be necessary to resolve this issue.

\section{Acknowledgements}

Our thanks go to the Ministry of Agriculture, Fisheries and Food, Scottish Office Agriculture, Fisheries and Environment Department and the Meat and Livestock
Commission for financial support and the Moredun Research Institute who provided facilities.

\section{References}

Farm Animal Welfare Council. 1994. Report on the welfare of sheep. Ministry of Agriculture, Fisheries and Food. Tolworth Tower, Surbiton, UK.

Kent, J. E., Molony, V. and Robertson, I. S. 1993. Changes in plasma concentrations of cortisol in lambs of three ages in the first three hours after three methods of castration and tail docking. Research in Veterinary Science 55: 246-251.

Kent, J. E., Moloney, V., Hosie, B. and Sheppard, B. 1997. Assessment of chronic inflammatory pain after rubber ring castration of six week old lambs. Proceedings of the Sheep Veterinary Society 21: 93.

Molony, V., Kent, J. E. and Robertson, I. S. 1993. Behavioural responses of lambs of three ages in the first three hours after three methods of castration and tail docking. Research in Veterinary Science 55: 246-251.

Molony, V., Kent, J. E. and Robertson, I. S. 1995. Assessment of acute and chronic pain after different methods of castration of calves. Applied Animal Behavioural Sciences 46: 33-48. 